\title{
Prevalence of SRY and DAX-1 gene deletion in patients with Cryptorchidism and Hypospadias - A Pilot study in North Indian Children
}

\author{
Krishna Mohan Gulla1, Inusha Panigrahi', R.K. Marwaha', K.L.N. Rao² \\ ${ }^{1}$ Department of Pediatrics, Advanced Pediatrics Centre, Post Graduate Institute of Medical Education and Research, Chandigarh, 160012, India, \\ ${ }^{2}$ Department of Pediatric Surgery, Advanced Pediatrics Centre, Post Graduate Institute of Medical Education and Research,Chandigarh, 160 012 , India
}

\section{A B S T R A C T}

Background: Cryptorchidism and hypospadias are common problems in males attending the pediatric surgery clinic. These two abnormalities are also associated with genetic syndromes/disorders of sexual development (DSD). Aims and Objectives: Aim of present study was to find out the prevalence of SRY and DAX-1 gene deletions in phenotypic males with cryptorchidism or hypospadias. Materials and methods: Children with cryptorchidism, or hypospadias attending the Pediatric Surgery OPD were enrolled for the study after informed consent. One blood sample $(4 \mathrm{ml})$ was taken from each patient for DNA analysis and PCR amplification of SRY and DAX-1 genes was done using the previously described primers. PCR for DAX and SRY genes was done according to a standard protocol. Results: The age ranged from 12 months to 144 months. Twentynine children had cryptorchidism and 22 had hypospadias. Out of 29 children having cryptorchidism, 11 had right side cryptorchidism and 7 had bilateral cryptorchidism. Out of 22 children having hypospadias, 13 had distal penile hypospadias. The DNA analysis showed amplification of DAX gene in all 51 patients. SRY gene showed amplification in 50/51 patients and one patient's DNA did not show amplification. Conclusion: More extensive studies are needed to explore the enigma of genetic basis involved in DSD. Cryptorchidism and hypospadias are anomalies with potentially severe consequences, such as infertility and testicular cancer, and more research efforts can help in characterization of cause of these abnormalities.

Key words: Cryptorchidism, Hypospadias, Disorders of Sexual Differentiation, SRY, DAX-1

\section{INTRODUCTION}

Disorders of sexual development (DSD) are one of the most difficult disorders to understand, evaluate and to treat. The development in those candidates is influenced by multiple factors such as exposure to androgens, sex chromosome, genes, brain structures as well as social circumstances and family dynamics. Cryptorchidism is defined as testis that is not $4 \mathrm{~cm}$ or more below the pubic tubercle in an infant of normal size. ${ }^{1}$ It is most common congenital urogenital anomaly in newborn. Temporal analyses suggest an increasing secular trend in the incidence during the last decades in some countries. ${ }^{2}$ However, there are still contrary reports. ${ }^{3,4}$ On the other hand, there is a general agreement on the seasonality of cryptorchidism with spring and autumn being the seasons of significantly highest (peak in March) and lowest (trough in September) incidence, respectively. ${ }^{5,6}$ Most researchers attribute the above phenomenon to analogous seasonal variations of sex hormones. Hypospadias is defined as arrest in the development of urethra spongiosum and ventral prepuce resulting in abnormal meatal opening on ventral surface of penis or perineum. The incidence is being 4-8/1000 live births. ${ }^{7,8}$ In developing countries like India, Pakistan and other southeast asian countries and as well as many African countries, due to lack of data no precise statement on incidence and prevalence may be given but due to its risk factors and awareness, 
its reporting is increasing. ${ }^{9}$ Several genes are involved in normal development, differentiation, descent and function of gonads. Of these the SRY gene is most frequently studied. DAX-1 gene is present on the short arm of $\mathrm{X}$ chromosome-Xp21.3. Several studies had shown that this gene is not required for either testicular or ovarian differentiation but a double dose of DAX-1 functions as an antitestis gene. ${ }^{10-13}$ But recently it has been proposed that DAX functions as an early mediator of testis development down stream to SRY. ${ }^{14}$ Moreover, it has been known that DSDs with the presence of the $\mathrm{Y}$ chromosome are associated with an increased risk for the development of Germ Cell Tumors. ${ }^{15,16}$ Cryptorchidism is also associated with decreased testicular function. In unilateral cryptorchidism, the incidence of infertility may be as high as $32 \%$ and up to $59 \%$ of men with bilateral cryptorchidism may be infertile despite surgical correction by orchidopexy. ${ }^{17-19}$ So we planned to do this study mainly for role of SRY and DAX gene deletions in Indian children with cryptorchidism and hypospadias.

\section{MATERIALS AND METHODS}

Consecutive children with cryptorchidism, or hypospadias attending the Pediatric surgery outpatient clinic of PGIMER during the period of 01-01-2010 to 31-12-2010 who fulfilled the criteria were included in study after informed consent. One blood sample $(4 \mathrm{ml})$ was taken from each patient in EDTA vial for DNA analysis. DNA PCR amplication was done using standard methods using previously described primers (Table 1). The gels were visualized under gel documentation system of Alpha Innotech Corporation.

\section{RESULTS}

Fifty-one children from different states surrounding Chandigarh were enrolled in the study. 20 were from Punjab, 12 were from Haryana, 8 were from Chandigarh, 4 were from Uttarakhand, 3 from Uttar Pradesh, 3 were from Himachal Pradesh and 1 from Bihar. The age ranged from 12 months to 144 months. Twenty-nine children had cryptorchidism and 22 had hypospadias. Out of 29 children having cryptorchidism, 11 had right side cryptorchidism, 11 had left side cryptorchidism, 7 had bilateral cryptorchidism (Figure 1). Out of 22 children having hypospadias, 13 had distal penile hypospadias, 9 had proximal penile hypospadias. Twelve children of cryptorchidism and nine children of hypospadias also had short stature (Figure 2). There was no family history of infertility or mental retardation in any of the enrolled children. PCR amplification of DAX gene (Figure 3) showed product of 601 base pairs in all 51 patients. PCR for SRY gene was done which showed amplification at 470 base pairs in 50 patients (Figure 4) and one patient's DNA did not show amplification (Figure 5).This was a child with cryptorchidism (Table 2). The DNA quality was rechecked by running on gel and spectrophotometry. Sample has been sent for complete gene sequencing.

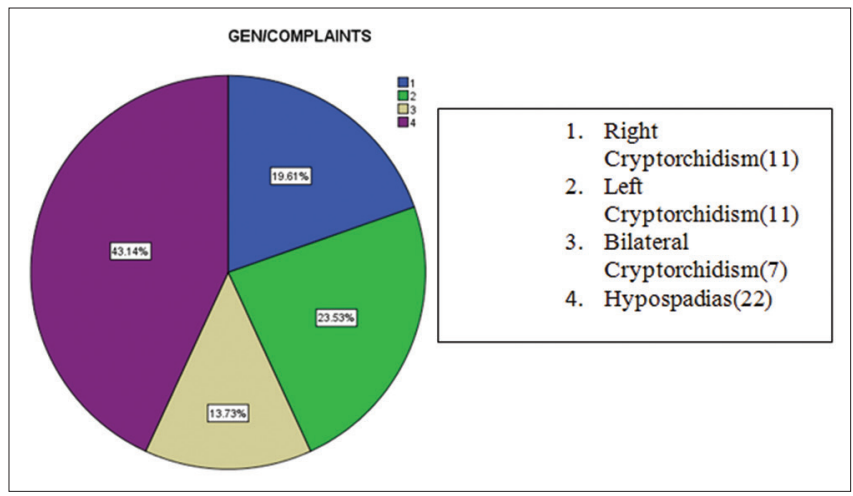

Figure 1: Pie chart showing distribution of patients with cryptorchidism and hypospadias

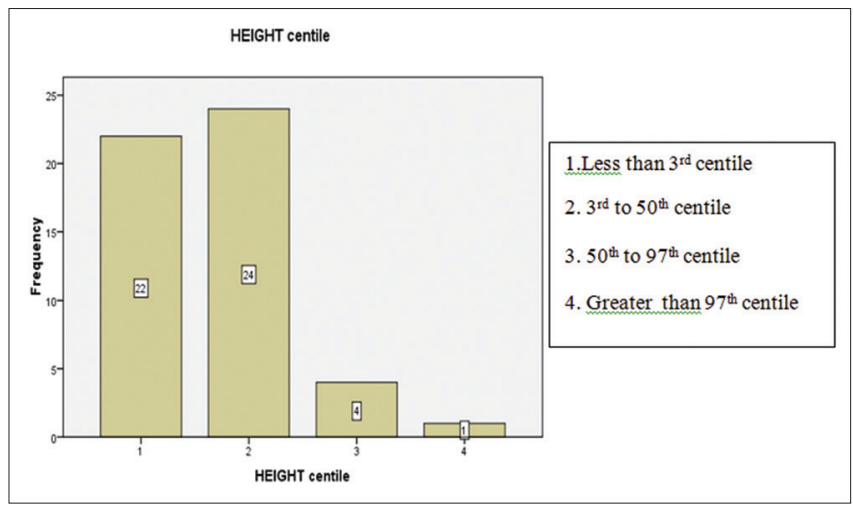

Figure 2: Height centiles of the study patients

\begin{tabular}{|c|c|}
\hline Gene & Primers \\
\hline DAX-Forward & 5'AGCAAAGGACTCTGTGGTGAG-3' \\
\hline DAX-Reverse & 5'-GCAGGTTCCATGAAATTGCTA- 3' \\
\hline SRY- Forward & 5'GAATATTCCCGCTCTCCGGA 3' \\
\hline SRY - Reverse & 5'-GCTGGTGCTCCATTCTTGAG-3' \\
\hline
\end{tabular}

\begin{tabular}{|c|c|c|c|}
\hline Phenotype & $\begin{array}{l}\text { No. of } \\
\text { patients }\end{array}$ & $\begin{array}{c}\text { SRY } \\
\text { amplification }\end{array}$ & $\begin{array}{c}\text { DAX } \\
\text { amplification }\end{array}$ \\
\hline Right cryptorchidism & 11 & 11 & 11 \\
\hline Left cryptorchidism & 11 & 10 & 11 \\
\hline B/L cryptorchidism & 7 & 7 & 7 \\
\hline Distal hypospadias & 13 & 13 & 13 \\
\hline Proximal hypospadias & 9 & 9 & 9 \\
\hline
\end{tabular}




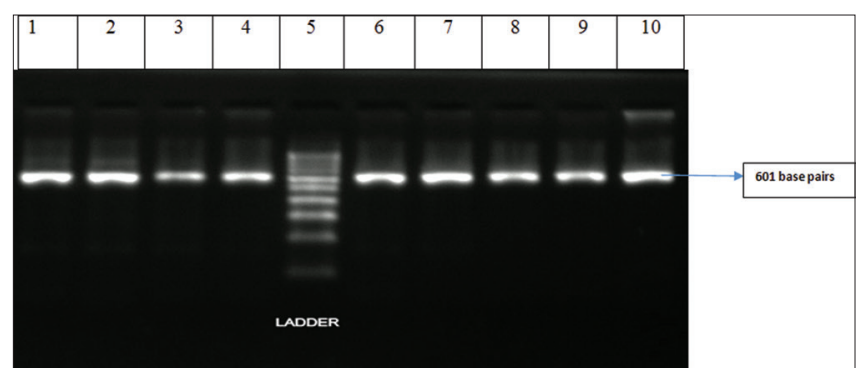

Figure 3: Gel Photograph showing DAX (exon 2) amplification along with DNA ladder in lane5

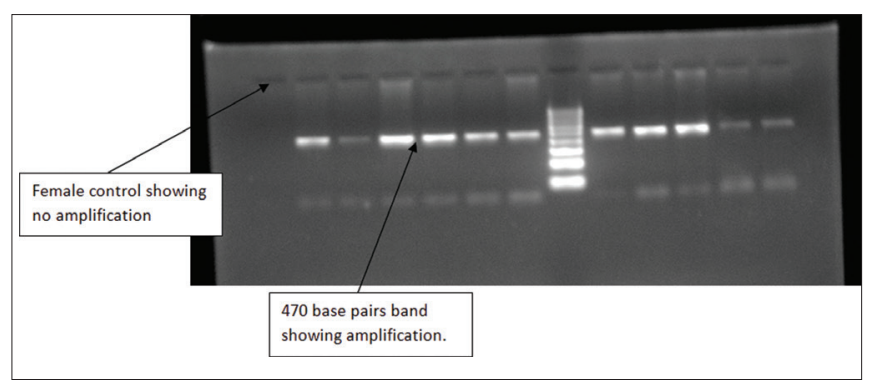

Figure 4: Gel Photograph showing SRY gene amplification along with the DNA ladder

\section{DISCUSSION}

Recently, terms like hermaphroditism, pseudoher maproditism, ambiguous genitalia are considered controversial. In recent years, the terminology 'disorders of sexual development (DSD)' is being increasingly used. This includes all the conditions of abnormal sexual development and differentiation. ${ }^{20}$ SRY acts by binding of the HMG box to a 6bp DNA sequence which bends DNA through a specific angle according to Harley et al 1992.This may promote association of regulatory elements bound to a far-flung region of DNA forming complex controls the activity of other genes. SRY gene is transcribed in many embryonic tissues which is then limited to testis after birth. It is a complex process by which SRY controls other genes. ${ }^{21}$ DAX 1 antagonises MIS expression during the male sexual development by inhibiting the synergistic interaction of SF1,WT1,factors that act to promote MIS. ${ }^{22}$

The role of genes like WT1, SOX9, SRYetc. in the development of primordial gonads is depicted in (Figure 6). A study done in Australia had used the Affymetrix Genome-Wide Human SNP Array 6.0 to analyse copy number variation in 23 individuals with unexplained 46, XY DSD due to gonadal dysgenesis (GD). They described three discrete changes in copy number that are the likely cause of the GD. Firstly, a large duplication on the X chromosome that included DAX1 (NR0B1). Secondly, a rearrangement that appears to affect a novel gonad-specific regulatory region in a known testis gene, SOX9. Functional analysis of potential SRY binding sites within this deleted

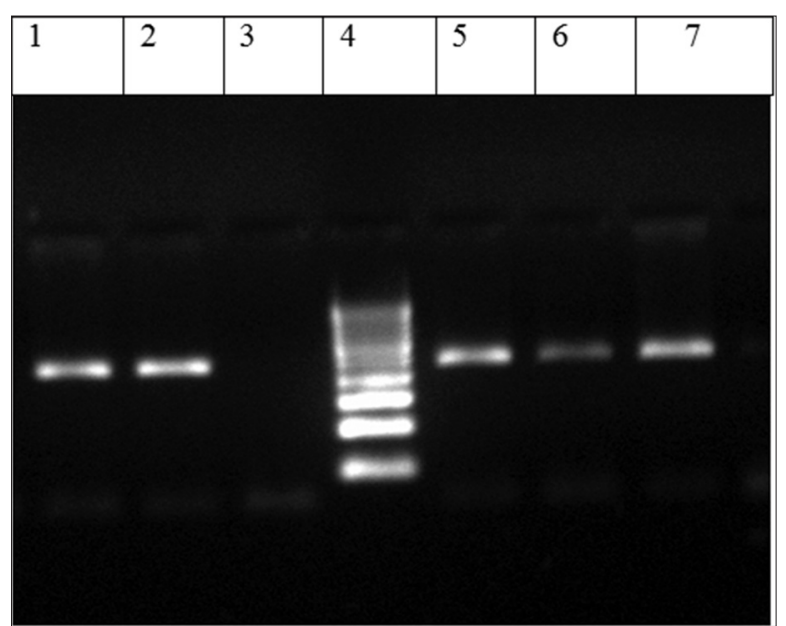

Figure 5: Lane 3 shows absence of SRY gene amplification in one patient in the gel. Lane 4 is the DNA ladder

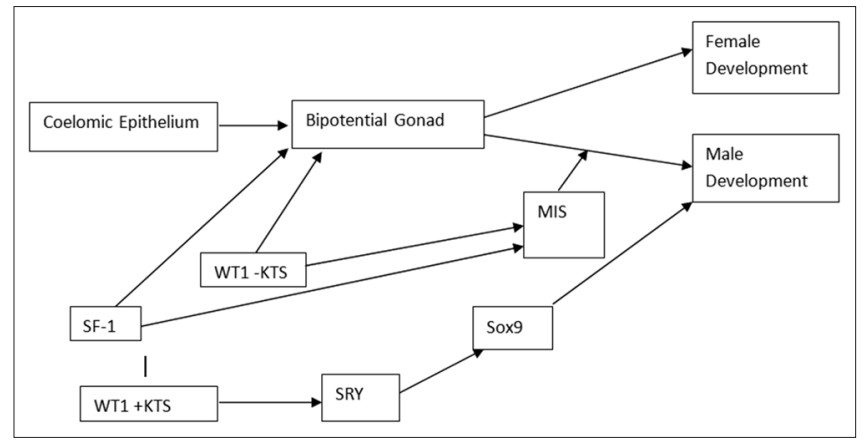

Figure 6: Model for the role of WT1 and SOX9 in gonad formation and sex determination.WT1-KTS variant possibly together ith SF-1 are required for the survival of gonadal mesenchyma. During male sex determination WT1+KTS isoforms are required for the activation or steability of SRY, which subsequently leads to activation of SOX9. SOX9, possibly with the help of SF-1 and WT-KTS,activates the MIS(Amb) promtor which in turn leads to degeneration of the mullerian duct.More over, SOX9 can initiate testis differentiation and must therefore have additional target genes, which regulate sertoli cell development. The absence of SRY in XX mice leads to the development of ovaries. Similarly, Frasier mutations interfere with activation of SRY, and hence, block male development

region identified five putative enhancers, suggesting that sequences additional to the known SRY-binding TES (Testis Specific Enhancer) enhancer influence human testis-specific SOX9 expression. Thirdly, a small deletion immediately downstream of GATA4, supporting a role for GATA4 in gonad development in humans. These CNV analyses give new insights into the pathways involved in human gonad development and dysfunction, and suggest that rearrangements of non-coding sequences disturbing gene regulation may account for significant proportion of DSD cases. They could not find any deletion in SRY gene of 23 patients. ${ }^{23} \mathrm{DAX}-1$ is required for both adrenal and gonadal development. It is expressed throughout the development of adrenals and its deletion results in AHC (Adrenal Hypoplasia Congenita). Hypogonadotropic 
hypogonadism is associated with AHC because DAX1 is also expressed in developing hypothalamus. ${ }^{24}$

The common embryological origin of gonads and adrenal glands and the localization of DAX1 within the DSS critical region on $\mathrm{X}$ chromosome, suggested that DAX1 might correspond to DSS. Because XY individuals deleted for DSS develop as males it can be proposed that DAX1 is required for ovarian but not testicular development and that its action should be turned off in XY genital ridge to avoid interference with testis development. ${ }^{25} \mathrm{~A}$ study done in Italy by Barbaro M, et al in 2008 had shown in $46 \mathrm{XY}$ gonadal dysgenesis identified two copy number variations, duplication of DAX1 gene, indicaing that DAX 1 is not required for the development of testis. But recent studies done in mice model suggest that DAX1 is required for the development of testis. A study done by Bouma et al. in Boston had shown evidence in mice that DAX1 plays an early essential role in fetal testis development. ${ }^{26}$ They hypothesised that upregulation of SOX9 expression in precursor somatic cells, a process required for their differentiation as sertoli cells, depends on the coordinated expression of DAX1, SRY and other genes. Studies on mice had shown that DAX acts as an important player in male sex determination in a position after SRY induction and before SOX upregulation. The gene targets are FGF9 (Fibroblast Growth Factor 9), Neurotropin3 (NTF3). The deletion of DAX1 lead to decreased amount of the above said targets and resulted in XY gonadal dysgenesis. ${ }^{27}$ In literature we could not able to find any study on humans supporting DAX 1 as a "Protestis" gene. Here we tried to briefly describe the mechanism of cryptorchidism and hypospadias. Gonads are positioned between two structures, the cranial suspensory ligament and gubernaculum and descent is divided into two phases-(1) transabdominal and (2) inguinoscrotal. There are few human studies for isolated cryptorchidism or hypospadias for SRY, DAX-1 gene deletion.

Several AZF (Azoospermic factor) abnormalities have been reported in males with infertility. SF1(NR5A1) mutations have been reported in $46 \mathrm{XY}$ individuals with severe penoscrotal hypospadias. ${ }^{28}$ An earlier study which was done by Bashamboo A et al, to study the sex chromosomal anamolies reported a patient with isolated cryptorchidism with SRY gene deletion, however some other patients in the same study did not have SRY deletion. ${ }^{29}$ Another study has reported $46 \mathrm{XX}$ male who presented with cryptorchidism, had Y chromosome fragment transferred to short arm of X-chromosome which might be telling the importance of SRY gene. Another study done was showing deletion in SRY promoter region in patient with severe hypospadias without cryptorchidism who has undergone 18 surgeries. ${ }^{30} \mathrm{DAX}-1$ deletion has been seen in XX males and mutations are also reported in patients with X linked adrenal hypoplasia congenital. ${ }^{31}$ DAX-1 mutations in other DSD phenotypes have not been well studied. DSD is one of the most difficult topics to understand. Cryptorchidism has been reported in 1.5$4.0 \%$ of fathers and $6.2 \%$ of brothers of cryptorchid subjects. ${ }^{32}$ But in our patients there was no family history of cryptorchidism. Only one study has reported a Yq deletion involving the entirety of the long arm in one cryptorchid subject; also in that case both testes were undescended, and other features were present (such as small chin, high palate, mental retardation). ${ }^{33}$ The SRY gene on the Y chromosome is the master switch for the determination of a testis, but other factors such as Wilms tumor 1 (WT1), SRY-box 9 (SOX9), Steroidogenic factor 1(SF1), DAX1, wingless-type mouse mammary 453 tumor virus integration site family, member 4(WNT4), required for testis development. Our study showed deletion of SRY gene in one patient, out of 51 which is approximately $2 \%$, consistent with the previous studies. A previous study by Bashamboo et al had also found SRY gene deletion in a patient with isolated cryptorchidism. ${ }^{29}$

A defect in any of these factors may lead to 46, XY gonadal disorder of sex development (DSD) including gonadal agenesis, dysgenesis and testicular regression. The first candidate gene to be analyzed in cases of 46, XY gonadal dysgenesis is SRY. However, mutations in the SRY gene accounts for only $10-15 \%$ of patients with 46 , XY gonadal dysgenesis. ${ }^{25}$ The consequence of absent or not fully functional testes is an absent or reduced production of testosterone and AMH that leads to the formation of female genitalia or ambiguous external genitalia depending on the degree of the defect. Multiple other genes are likely to be involved the 46XY DSDs other than SRY gene such as Insuline like3/relaxin like factor gene. ${ }^{34}$ DAX1 shows sexually dimorphic gonadal expression. It is down regulated in the developing testis. Studies in mouse models support DAX1 as having both pro-testis and anti-testis functions. ${ }^{14,24,26}$ These studies indicate that a critical level of DAX1 is required for proper testis cord formation-levels above or below this level interfere with the early stages of testicular differentiation (e.g, a duplication interferes with SRY function, while a loss of function retards early cord organization on a susceptible genetic background). As testis development proceeds, DAX1 is down-regulated, that is it antagonises the SF1/WT1/SOX9 activation of AMH. Hence, DAX1 has dynamic effects on the developing testis that changes over time. ${ }^{27}$ However, in our study we could not find any deletion in DAX (exon 2) gene in any of the patients with either cryptorchidism or hypospadias, suggesting that further studies of DAX gene are required. 
In our study, $43 \%$ of the enrolled children had short stature which is likely multifactorial involving genetic and environmental factors. Some genetic syndromes associated with genital abnormalities include Facio Genital Dysplasia (FGD), Smith Lemli Opitz syndrome, MURCs associations, Noonan syndrome and WAGR syndrome. WT1 gene, implicated in WAGR syndrome is relatively well studied gene. Further research would give more insights into whether genes involved in these syndromes can also lead to isolated genital abnormality as part of minimal expression of the genetic defect.

\section{CONCLUSION}

Pathogenesis of DSDs is still not fully understood all across the globe. Our's is a pilot study with limited sample size. As the geographical, environmental factors may affect the phenotypic expression of genes, more and extensive studies are needed to explore the enigma of multiple genetic factors involved in DSD in Indian scenario. Epigenetic effects or associations may alter expression or presentation of abnormal gene in the gonadal pathways.

\section{REFERENCES}

1. Williams text book of endocrinology.13th edition pp no:728

2. Berkowitz GS, Lapinski RH, Dolgin SE, Gazella JG, Bodian CA and Holzman IR. Prevalence and natural history of cryptorchidism. Pediatrics 1993; 92: 44-49.

3. Ghirri P, Ciulli C, Vuerich M, Cuttano A, Faraoni M, Guerrini L, et al. Incidence at birth and natural history of cryptorchidism: A study of 10,730 consecutive male infants. J Endocrinol Invest2002; 25: 709-715.

4. Kaleva M, Virtanen H, Haavisto AM, Main K, Skakkebaek NE and Toppari J. Incidence of cryptorchidism in Finnish boys. Horm Res 2002; 55: 54

5. Berkowitz GS, Lapinski RH, Godbold JH, Dolgin SE and Holzman IR. Maternal and neonatal risk factors for cryptorchidism. Epidemiology1995; 6: 127-131.

6. Jackson $M B$ and Swerdlow AJ. Seasonal variations in cryptorchidism. J Epidemiol Community Health 1986; 40: 210-213.

7. Paulozzi LJ, Erickson JD and Jackson RJ. Hypospadias trends in two US surveillance systems. Pediatrics 1997; 100:831-834.

8. Belman $A B$. Hypospadias and other urethral abnormalities. Clin. Ped Urol.3 $3^{\text {rd }}$ ed,vol 1.Philadelphia: WB Saunders, 1992;619-663.

9. Carmichael SL, Shaw GM and Lammer EJ. Environmental and ruling out the possibility of many other and genetic contributors to hypospadias: A review of the epidemiologic evidence. Birth Defects Res A Clin Mol Teratol 2012; 94:499-510.

10. Bardoni B, Zanari E, Guioli S, Floridia.G, Worley.KC, Tonini.E et al. A dosage sensitive locus at chromosome Xp21 is involved in male to female sex reversal. Nat Genet 1994; 7:497-501.

11. Swain A, Narvaez, Burgoyne P, CamarenoG and Lovell-Badge R. Dax antagonises SRY action in mammalian sex determination. Nature 1998; 391:761-767.
12. Dumic M, Lin-Su K, Leibel NI, Ciglar S, Vinci G, Lasan R, et al. Report of fertility in a woman with a predominantly 46XY karyotype in a family with multiple disorders of sexual developement. J Clin Endocrinol Metab 2008; 93:182-189.

13. Baumstark A, Bark G, Djalali M, Geerkens.C, Mitulla.B, Torstein M, et al. Xp duplications with and without sex reversal. Hum Genet 1996; 97:79-86.

14. Meeks $\mathrm{JJ}$, Weiss $\mathrm{J}$ and Jameson JL. Dax1 is required for testis determination. Nat Genet 2003; 34:32-33.

15. Scully RE. Gonadoblastoma. A review of 74 cases. Cancer 1970; 25:1340-1356.

16. Verp MS and Simpson JL. Abnormal sexual differentiation and neoplasia. Cancer Genet Cytogenet 1987; 25:191-218.

17. Lee PA, O'Leary LA, Songer NJ, Coughlin MT, Bellinger MF and LaPorte RE. Paternity after unilateral cryptorchidism (a controlled study). Pediatrics 1996; 98:676-679.

18. Lee PA, O'Leary LA, Songer NJ, Coughlin MT, Bellinger MF and LaPorte RE. Paternity after bilateral cryptorchidism. Arch Pediatr Adolesc Med 1997;151:260

19. Mathews R, Gearhart JP, Pohl HG, Belman AB, Costable RA, Kennedy WA, et al. The undescended testis (an update). Dialogues Pediatr Urol 1997; 20:1-8.

20. Lee PA, Houk CP, Ahmed SF and Hughes I. Participants in the International Consensus Conference on Intersex organised by the Lawson Wilkins Pediatric Endocrine Society and the European Society for Pediatric Endocrinology. Pediatrics 2006; 118; e488-e500.

21. The Genetics and Biology of sex determination: Novartis Foundation Symposium. 2002: 244:136-156.

22. Iyer AK and McCabe ER. Molecular mechanisms of DAX1 action. Mol Genet Metab 2004; 83:60-73.

23. White S, Ohnesorg T, Notini A, Roeszler K, Hewitt J, Daggag H, et al. Copy number variation in patients with Disorders of Sex Development due to 46XY, gonadal dysgenesis. PloS ONE 2011:6:3: E17793.

24. Swain A, Zanaria E, Hacker A, Lovel BR and Camerino G. Mouse DAX 11 expression is consistent with a role in sex determination as well as in adrenal hypothalamus function. Nat Genet 1996:12:404-409.

25. Barbaro M, Cicognani A, Balsamo A, Lofgren A, Baldazzi L, Weldel A, et al. Gene dosage imbalances in patients with $46 X Y$ gonadal DSD detected by an in-house-designed synthetic probe set for multiplex ligation-dependent probe amplification analysis. Clin Genet 2008; 73: 453-464.

26. Bouma GJ, Albrecht KH, Washburn LL, Recknagel AK, Churchill GA and Eicher EM. Gonadal sex reversal in mutant Dax1 XY mice: A failure to upregulate Sox9 in pre-Sertoli cells. Development 2005; 132:3045-3054.

27. Lidbrook LM and Harley VR. Trends Endocrinol Metab 2004; 15:116-121.

28. Kohler B, Lin L, Mazen I, Cetindag C, Biebermann H, Akkurt I, et al. The spectrum of phenotypes associated with mutations in steroidogenic factor 1 includes severe penoscrotal hypospadias in 46XY males withotut adrenal insufficiency. Eur $\mathrm{J}$ Endocrinol 2009; 161(2):237-242.

29. Bashamboo A, Rahaman MM and Prasad A. Fate of SRY, PABY, DYS1, DYZ3 and DYZ1 loci in Indian patients harboring sex chromosomal anomaly. Mol Hum Reprod 2005;11:117-127.

30. Assmpcao JG, Ferraz LF, Benedetti CE, Maciel-Guerra G and Marques-de-Faria AP. A naturally occurring deletion in the SRY promoter region affecting the $\mathrm{Sp} 1$ binding site is associated with sex reversal. J Endocrinol Invest 2005; 28:651-656.

31. Garica-Malpartida K, Gomez-Balaguer M, Sola-Izquierdo E, Fuentes-Pardilla MJ and Jover-Fernandez A. A novel mutation 
in DAX1 (NROB1) causing X-linked adrenal hypoplasia cogenita: Clinical, hormonal and genetic analysis.Endocrine 2009:36:275-280.

32. Czeizel A, Erodi E and Toth J. Genetics of undescended testis. J Urol 1981;126:528 -529.

33. Salo $\mathrm{P}$, Ignatius $\mathrm{J}$ and Simola KOJ. Clinical features of nine males with molecularly defined deletions of the $\mathrm{Y}$ chromosome long arm. J Med Genet 1995; 32:711-715.

34. Tomboc M, Lee PA, Mitwally MF, Schneck FX, Bellinger M and Witchel SF. Insulin-like3/relaxin- like factor gene mutations are associated with cryptorchidism. J Clin Endocrinol Metab 2000; 85:4013.

Authors Contribution:

KMG - Conducted the study and prepared manuscript; IP - Guide to the project and reviewed the manuscript; RKM - Co-guide to the project; KLNR - Co-guide

to $\mathrm{KMG}$ and reviewed manuscript.

Source of Support: None declared, Conflict of Interest: None declared. 